A - Research concept and design

B - Collection and/or assembly of data

$\mathrm{C}$ - Data analysis and interpretation

D - Writing the article

E - Critical revision of the article

F - Final approval of article

\section{Effect of Aerobic Exercise Training on Leptin and Liver Enzymes in Non-diabetic Overweight Hepatitis C Men}

\author{
Ali Mohamed Ali Ismail*1,A,C-D,F (D), Ahmed Mahmoud Nasr Tolba ${ }^{2, B, E-F}$ (iD \\ , El-Sayed Essam El-Sayed Felaya ${ }^{1, B, E-F}$ (D) \\ ${ }^{1}$ Department of Physical Therapy for Cardiovascular / Respiratory Disorder \\ and Geriatrics, Faculty of Physical Therapy, Cairo University, Giza, Egypt \\ ${ }^{2}$ Basic Science Department, Faculty of Physical Therapy, Delta University for \\ Science and Technology, International Coastal Road, Gamassa, Dakahlia, \\ Egypt
}

*Correspondence: Ali Mohamed Ali Ismail; Lecturer, Department of Physical Therapy for Cardiovascular / Respiratory Disorder and Geriatrics, Faculty of Physical Therapy, Cairo University, Giza, Egypt; email: ali.mohamed@pt.cu.edu.eg

\begin{abstract}
Introduction: Leptin is one of the new adipokines that reflects the pathological status of liver tissue in the chronic hepatitis $\mathrm{C}$ virus (HCV). This study aimed to investigate the leptin and liver enzymes responses to aerobic exercise (AE) in overweight nondiabetics with HCV.

Material and methods: Forty nondiabetic non-cirrhotic HCV men aged 40-60 years old with a body mass index (BMI) varied from 25-29.9 kg/m2 were divided randomly to study and control groups. The study group $(\mathrm{n}=20)$ received a 3-session continuous moderate-intensity AE per week for 12 weeks while the control group $(\mathrm{n}=20)$ were advised to maintain their normal level of physical activity. Pre and post measurements of weight, BMI, waist circumference, fasting blood glucose (FBG), alanine transaminase (ALT), aspartate transaminase (AST), and leptin were measured for all forty patients.

Results: Statistical ANOVA analysis revealed a post-treatment significant statistical decrease of all variables within the study group $(p<0.05)$ while the control group showed a non-significant difference of all measurements. Post-treatment between-group analysis showed a significant statistical difference in FBG, ALT, AST, and leptin in favor of the study group.

Conclusions: To restore the normal hepatic cellular functions and to prevent HCV-induced hepatic fibrosis, AE is a strong therapeutic modality that lowers leptin levels via weight maintenance and/or loss, increased glucose uptake, and declined liver enzymes.
\end{abstract}

Keywords: overweight, aerobic exercise, Leptin, Liver enzymes, Hepatitis C

\section{Introduction}

Hepatitis $\mathrm{C}$ virus (HCV) is one of the main human pathogens that causes chronic liver diseases as hepatic cirrhosis and hepatocellular carcinoma in addition to the increased rate of mortality. Besides the highly-estimated prevalence rate in middle-aged men, 32\%, Egypt represents the uppermost prevalence of $\mathrm{HCV}$ around the world [1]. HCV-induced hepatic fibrosis rates are lower in women than men due to the probable increase of $\mathrm{HCV}$ clearance rate augmented by the anti-fibrogenic effect of estrogen [2].

$\mathrm{HCV}$ is the main risk factor for the development of diabetes mellitus (DM) due to the massive destruction

This is an Open Access journal, all articles are distributed under the terms of the Creative Commons Attribution-NonCommercial-ShareAlike 4.0 International (CC BY-NC-SA 4.0). License (http://creativecommons. org/licenses/by-nc-sa/4.0/). 
of pancreatic $\beta$-cells induced by HCV [3]. Insulin resistance (IR) is a pro-fibrogenic stimulus to liver tissues in HCV patients because many reports stated the presence of impaired glucose metabolism in both muscular and hepatic tissues of nondiabetic HCV patients [4].

Being a serious endocrine organ, adipose tissue is the main source of adipokines and biologically-effective polypeptides like leptin. Leptin plays a strong metabolic action in the control of food intake, sympathetic tone, energy expenditure in conditions of excess energy, neuroendocrine function, appetite, carbohydrates and lipids metabolism, the action of insulin receptors, and secretion of insulin and hormones utilized in lipid metabolism [5].

$\mathrm{HCV}$ is now expressed as metabolic liver disease and there are numerous non-invasive plasma biomarkers - including leptin - have been suggested to reflect the $\mathrm{HCV}$-induced progressive fibrotic changes of hepatic tissues. Various studies recorded the involvement of different adipocytokines in the $\mathrm{HCV}$-associated fibrogenesis of hepatic tissues due to the direct fibrotic stimulatory signals to hepatic stellate cells and the indirect stimulation to inflammatory cells as Kupffer cells and macrophages [6]. Elevated serum leptin levels are positively correlated with the body mass index (BMI), fat mass, hepatic steatosis, the severity of hepatic fibrosis stages, and physical fatigue in HCV patients [7].

Despite the known role of regular training in the inhibition/prevention of hepatic disease progression by modulating leptin and insulin signaling/levels [8], the available studies in the area of $\mathrm{HCV}$ and leptin are very scarce [9]. This study aimed to investigate the effect of 12-week aerobic training on serum leptin and liver enzymes in nondiabetic overweight men with $\mathrm{HCV}$.

\section{Materials and methods}

\section{Ethics}

Besides receiving a signed consent form from every participant and planning this trial according to the recommended declarations of Helsinki, this study was approved (under the number of P.T.REC/012/002650) by the Local Ethical Institutional Committee for Human Scientific Research, Physical Therapy Faculty, Cairo University.

\section{Inclusion criteria}

Forty men aged 40-60 years old with HCV at least from 6 months were recruited from The National Hepatology and Tropical Medicine Institute with a BMI $\geq$ 25 to less than $30 \mathrm{~kg} / \mathrm{m}^{2}$, fasting blood glucose (FBG) levels less than $100 \mathrm{mg} / \mathrm{dl}$, and a waist circumference (WC) less than $102 \mathrm{~cm}$ during the period from February-November 2020.

\section{Exclusion criteria}

A physician screened the patients to exclude those with cirrhotic or hepatocellular carcinoma, renal or respiratory problems, cardiovascular and neurologic diseases, and hypertension. The individuals who participated in any form of physical training or diet counseling in the last 3 months were also excluded.

\section{Randomization}

An individual - not involved in application of this clinical trial - prepared a randomized computer-developed group list then the patients were divided randomly to study or control groups (Fig. 1).

\section{Intervention}

The study group $(n=20)$ received a 3-month aerobic training, 3 sessions weekly, on an electronic treadmill with no inclination. Every session was started with a 5-minute warming-up then a 30-minute moderate-intensity aerobic training at $60-75 \%$ of maximal heart rate (220-age) then the session was ended with 5 minutes of cooling down [10]. The control group $(n=20)$ were advised to maintain their normal daily physical activity.

\section{Primary outcomes}

Five milliliters of blood were obtained from the antecubital vein to assess the serum aspartate transaminase (AST) and alanine transaminase (ALT) (liver enzymes were measured by Hitachi 971 device, Mannheim). Serum leptin was measured by Leptin ELISA Kits, Diagnostic Biochem, Canada.

\section{Secondary outcomes}

With an empty bladder and stomach, weight was measured for every participant. The BMI was obtained from dividing the weight $(\mathrm{kg})$ on squared height (meter). WC was measured with an inelastic tape between the iliac crest and lower ribs. FBG levels were measured using (On Call ${ }^{\circledR}$ Plus Acon, REF G113 - 214, made in China). All measurements (primary and secondary were applied before and after the 3-month study period for both allocated groups)

\section{Statistical analysis}

Obtained from a 10-subject pilot study, a size effect equal to 0.83 for the main outcome variable, leptin, was detected by calculating the sample size through the German power analysis program $\left(\mathrm{G}^{*}\right.$ Power version 3.1.9.2, Franz Faul, Uni Kiel) with T-test. The suggested minimum sample size for this trial was 38 hepatitis C patients with the type I and type II error rates was programmed at $5 \%$ and $80 \%$ power respectively.

The Shapiro-Wilk's test showed a normal distribution of the data so the unpaired test was used to examine 


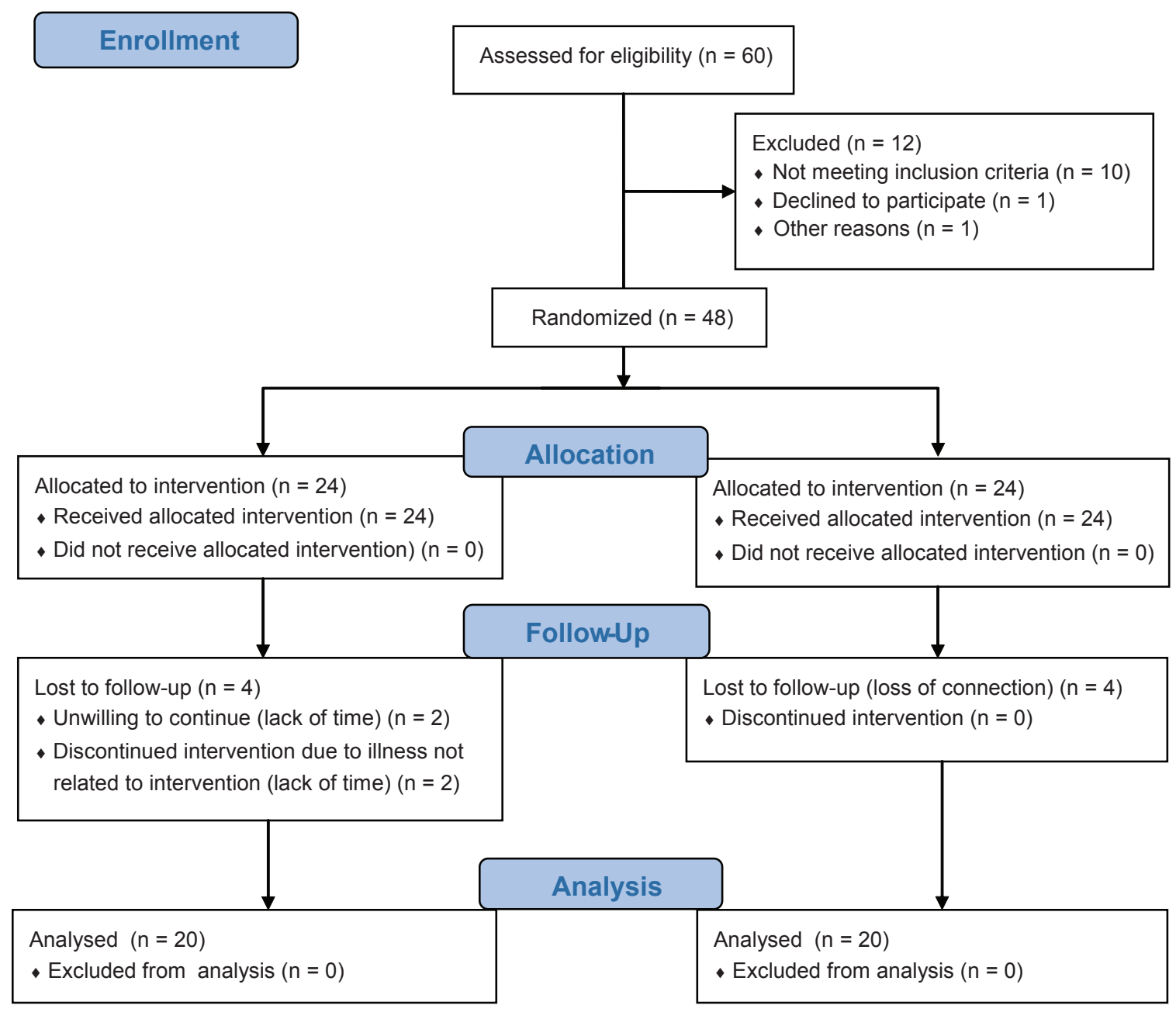

Fig.1. Consort flow diagram for the study

the pretreatment significance of anthropometric data between groups. Also, the within - and among-group statistical significances were tested by the parametric test, ANOVA. The analysis of data - at a significant P-value level less than 0.05 - was done by version 18 of the SPSS program (IBM Corp. Chicago. SPSS Inc.).

\section{Results}

Pre-treatment among-group anthropometric (weight, height, BMI, and WC) analysis by unpaired test showed a non-significant statistical difference (Tab. 1). There was a significant statistical decrease in all variables within the study group while the control group showed a non-significant statistical difference in the all measured variables. Among-group comparison of post-treatment values showed a significant statistical difference in FBG, ALT, AST, and leptin values in favor of the study group while the anthropometric variables showed a non-significant difference (Tab. 2).

\section{Discussion}

Besides the induced-deterioration of liver disease by high leptin levels, overweight is the main risk factor for the development of IR and type 2 DM among $\mathrm{HCV}$ patients [11]. Besides its importance for maintaining the normal mental, physical, psychological health issues [12-15], exercise promotes the health of the liver, relieves the side effects of medications, improves immunity, promotes the sense of well-being, enhances weight maintenance and/or loss, lowers the sensation of chronic fatigue, improves blood oxygen levels, and enhances the full-energized sensation by the excretion of endorphins in HCV patients [16].

Despite the gained minimal anthropometric and FBG changes, a 12-week aerobic exercise resulted in a highly significant statistical decrease of leptin and liver enzymes in overweight non-diabetic HCV men.

Decreased serum leptin levels after chronic physical training may be justified by glycogen evacuation, glycolysis inhibition, increased glucose utilization, 
Tab.1. Pre-treatment anthropometric data in both groups

\begin{tabular}{lccc}
\hline Variable & Study group & Control group & P value \\
\hline Age $($ year $)$ & $47.85 \pm 5.38$ & $49.40 \pm 5.30$ & 0.364 \\
Weight $(\mathrm{kg})$ & $79.05 \pm 4.05$ & $78.60 \pm 4.56$ & 0.744 \\
Height $(\mathrm{cm})$ & $168.30 \pm 3.89$ & $169.05 \pm 5.12$ & 0.605 \\
BMI $\left(\mathrm{kg} / \mathrm{m}^{2}\right)$ & $27.86 \pm 1.01$ & $27.50 \pm 1.31$ & 0.342 \\
WC $(\mathrm{cm})$ & $89.45 \pm 5.10$ & $88.80 \pm 5.30$ & 0.695 \\
\hline
\end{tabular}

Data are expressed as mean \pm standard deviation; BMI - body mass index; WC - waist circumference; P value significance $<0.05$.

Tab.2. Within - and among-result comparisons of pre \& post data in both groups

\begin{tabular}{|c|c|c|c|}
\hline Variable & Study group $(n=20)$ & Control group $(\mathrm{n}=20)$ & Among-group P-value \\
\hline Pre-weight (kg) & $79.05 \pm 4.05$ & $78.60 \pm 4.56$ & 0.744 \\
\hline Post-weight & $78.71 \pm 4.27$ & $78.77 \pm 4.52$ & 0.966 \\
\hline P-value within group & $0.041 *$ & 0.277 & \\
\hline Pre-BMI $\left(\mathrm{Kg} / \mathrm{m}^{2}\right)$ & $27.86 \pm 1.01$ & $27.50 \pm 1.31$ & 0.342 \\
\hline Post-BMI & $27.65 \pm 1.02$ & $27.57 \pm 1.41$ & 0.834 \\
\hline P-value within group & $0.002 *$ & 0.292 & \\
\hline Pre-WC & $89.45 \pm 5.10$ & $88.80 \pm 5.30$ & 0.695 \\
\hline Post-WC & $88.40 \pm 5.87$ & $89.00 \pm 5.43$ & 0.739 \\
\hline P-value within group & $<0.001 *$ & 0.458 & \\
\hline Pre-FBG (mg/dl) & $89.50 \pm 5.47$ & $90.95 \pm 5.16$ & 0.394 \\
\hline Post-FBG & $87.65 \pm 5.52$ & $91.70 \pm 6.26$ & $0.037^{*}$ \\
\hline P-value within group & $0.035^{*}$ & 0.380 & \\
\hline Pre-ALT (u/L) & $77.35 \pm 26.57$ & $74.25 \pm 26.76$ & 0.715 \\
\hline Post-ALT & $57.9 \pm 24.38$ & $74.55 \pm 26.91$ & $0.047^{*}$ \\
\hline P-value within group & $<0.001 *$ & 0.898 & \\
\hline Pre-AST (u/L) & $61.50 \pm 31.04$ & $63.90 \pm 31.29$ & 0.809 \\
\hline Post-AST & $45.85 \pm 24.24$ & $64.25 \pm 31.45$ & $0.045^{*}$ \\
\hline P-value within group & $<0.001 *$ & 0.916 & \\
\hline Pre-leptin (ng/ml) & $7.40 \pm 1.31$ & $7.35 \pm 1.38$ & 0.907 \\
\hline Post-leptin & $6.29 \pm 1.63$ & $7.46 \pm 1.32$ & $0.017^{*}$ \\
\hline P-value within group & $<0.001 *$ & 0.596 & \\
\hline
\end{tabular}

Data are expressed as mean \pm standard deviation; $\mathrm{mg} / \mathrm{dl}$ - milligram per deciliter; $\mathrm{u} / \mathrm{L}$ - unit per liter; $\mathrm{ng} / \mathrm{ml}$ - nanogram per milliliter; AST - aspartate transaminase; ALT - alanine transaminase; * significant P-value, P value significance $(<0.05)$.

modulation of energy balance, and increased sensitivity to hormones involved in both fat and carbohydrate metabolism as insulin, thyroxin, and cortisol [16].

Increased sensitivity to insulin after prolonged exercise may be explained by repetitive stimulation to many protein carriers - including glucose transporter-4 - that increase the utilization of glucose uptake into the cellular membrane of active skeletal muscles, the responsible tissue for consuming $80 \%$ of circulating glucose [17].

The mechanism of reduced serum levels of ALT and AST levels in response to aerobic exercise in $\mathrm{HCV}$ patients may be explained by the enhanced immune system, increased production of anti-inflammatory markers, increased fighting to infected hepatic cells, 
reduction of viral replication, lower rates of infection spread, increased resistance of hepatic cells to inflammation, and prevention of further cellular hepatic inflammation [18].

Lowered lipid oxidation and steatosis of the whole body, increased metabolism of fatty acids and hepatic lipids, stimulation of hepatic and muscular protein kinases, lowered production of hepatic glucose, and inhibited proliferation of hepatic stellate cells may be the responsible causes of decreased liver enzymes after a 3-month aerobic training in patients with HCV [19].

The current study was supported by Nasif et al. [18] who stated that an eight-week moderate-intensity training was able to restore the normal hepatic cellular function in addition to increased resistance to infection by enhanced immune cytokines and liver enzymes (AST and AST) in HCV patients. The gained modulatory changes of hepatic lipid metabolism after a 6-week aerobic training in nonalcoholic fatty liver patients is the cause of liver enzymes decrease [20]. A twelveweek aerobic exercise improved fatigue symptoms in non-cirrhotic HCV patients may be due to the observed decline of systemic inflammatory markers [10].

In addition to the acquired improvement of quality of life, exercise - as an adjunctive therapeutic modality in a 15-month weight maintenance and/or loss program - resulted in decreased serum insulin and liver enzymes in overweight patients with chronic liver disease [21]. The improved virological response may be the cause of improved IR after aerobic exercise in HCV patients with metabolic syndrome [22].

The regular walking - combined with a diet regimen - declined the occurrence rate of HCV via improved IR, liver enzymes, leptin levels, and body fat [23]. A pilot study recommended the importance of exercise in the enhancement of physical and psychological HCVrelated aspects of life [24].

The decreased levels of serum leptin and insulin in sedentary females may be related to decreased levels of lipids after an eight-week exercise [5]. Due to the expressive changes in the genes of adipokines located in adipose tissue, a 8-week aerobic training is considered an effective intervention in decreasing weight and leptin in overweight women [25].

An eight-week supervised aerobic training program resulted in a decrease of both leptin and anthropometric indices in overweight healthy young men [26]. A twelve-week moderate-intensity aerobic exercise resulted in a highly statistically significant improvement of leptin in sedentary obese men [27]. A six-week aerobic training appeared to be a non-prescriptive treatment tool to improve IR by lowering the levels of insulin and adipokine mediators - including leptin - in sedentary men [28].
On the other hand, despite the importance of regular physical activity in the prevention of risk factors including obesity and high blood glucose levels - for liver diseases, an eight-week aerobic exercise revealed no significant effects on liver enzymes of older women [29].

Despite improved muscular strength and IR via an eight-week resistive training, a non-significant change of leptin - in sedentary overweight men - was noted. Leptin has not improved due to the not enough reduced amount of both body mass and fat to produce significant changes in adipokines levels [30].

Despite the hopeful improvement of insulin levels in 55 older adults with mild cognitive impairment after a 16-week aerobic training, leptin levels showed nonsignificant improvement [31]. Serum leptin did not show a significant change after the 8 -week training period may be due to the selected type and intensity of exercise parameters (high-intensity interval training) [16].

\section{Limitations}

There were many limitations in this study as small number of patients, nonparticipating females, the short duration of exercise, and loss of follow up should be examined in future studies.. Investigating the response of leptin and liver enzymes to aerobic exercise training plus diet control versus exercise should be addressed in future studies.

\section{Conclusions}

Despite the minimal anthropometric changes, aerobic training is considered a good approach for weight control (loss and/or maintenance) in nondiabetic overweight men with HCV. To prevent the development of IR, type $2 \mathrm{DM}$, and hepatic steatosis (the main risk factors for hepatic fibrosis in patients with $\mathrm{HCV}$ ), regular exercise is very important to lower serum leptin and liver enzymes via increased insulin sensitivity and glucose utilization in patients with $\mathrm{HCV}$.

\section{Funding}

This research received no external funding.

\section{Conflicts of interest}

The authors declare no conflict of interest.

\section{References}

1. Soliman G, Elzalabany MS, Hassanein T, Miller FD. Mass screening for hepatitis B and C in Southern Upper Egypt. BMC public health. 2019 Oct 22; 19(1): 1-7. 
2. Elshimi E, Morad W, Mohamad NE. Male sexual dysfunction among Egyptian patients with chronic hepatitis $\mathrm{C}$ virus infection before and after direct-acting antiviral drugs. J Sex Med. 2019 Mar; 16(3): 402-9.

3. Kuna L, Jakab J, Smolic R, Wu GY, Smolic M. HCV extrahepatic manifestations. J Clin Transl Hepatol. 2019 Jun 28; 7(2): 172-2.

4. Muzzi A, Leandro G, Rubbia-Brandt L, James R, Keiser O, Malinverni $\mathrm{R}$, et al. Insulin resistance is associated with liver fibrosis in non-diabetic chronic hepatitis C patients. J Hepatol. 2005 Jan; 42(1): 41-6.

5. Dundar A, Kocahan S, Sahin L. Associations of apelin, leptin, irisin, ghrelin, insulin, glucose levels, and lipid parameters with physical activity during eight weeks of regular exercise training. Arch Physiol Biochem. 2019 July 10; 1-5.

6. Abdel-Messeih PL, Mansour HH, Ibrahim DR. Evaluation of chemerin and leptin in serum of chronic hepatitis C patients. J Histol Cell Biol. 2018; 1(1): 8-12.

7. Liu ZW, Zhang N, Han QY, Zeng JT, Chu YL, Qiu JM, et al. Correlation of serum leptin levels with anthropometric and metabolic parameters and biochemical liver function in Chinese patients with chronic hepatitis C virus infection. World J Gastroenterol. 2005 Jun 24; 11(22): 3357-2.

8. Anaruma CP, Pereira RM, da Cruz Rodrigues KC, da Silva ASR, Cintra DE, Ropelle ER, et al. Rock protein as cardiac hypertrophy modulator in obesity and physical exercise. Life Sci. 2019; 116955.

9. de Sousa Fernandes MS, de Lima EA, da Silva LO, Oliveira TL, Santos GCJ, da Costa Ribeiro I, et al. Can Physical Activity Help in Hepatitis C Treatment? A Mini Review. J Gastroenterol Hepatol Res. 2019; 8(1): 2789-2.

10. Shehab MAE, Osama HA. Impact of aerobic exercises on fatigue related to systemic inflammation in patients with hepatitis C virus. Adv Res Gastroenterol Hepatol. 2017; 2 (3): 555587.

11. Elgendi S, AmanyShebl W, Sliem M, Gary FA. The effectiveness of nursing educational intervention on improving fatigue levels among Egyptian patients with chronic hepatitis $\mathrm{C}$ virus undergoing antiviral therapy.' IOSR-JNHS. 2018 Mar-Apr; 7(2), 68-7.

12. Ismail AMA. Cancelled elderly exercise sessions during the COVID-19 crisis: can physical therapists help from their homes? Eur J Physiother. 2020 May 19; 22(4): 235.

13. Ismail AMA. Online exercise rehabilitation to stable COPD patients during the second COVID wave: are physiotherapists able to help? Adv Rehab. 2020 Dec; 34(4): 48-9.

14. Ismail AMA. Robot-assisted rehabilitation: it is the time for utilisation in in-patient health care facilities to maintain the activity of the elderly during the COVID19 pandemic. Int Marit Health. 2021; 72(1): 80-1.

15. Ismail AMA, Abdelghany AI, Elfahl AMA. Immediate effect of interscapular cupping on blood pressure, oxygen saturation, pulse rate and chest expansion in sedentary smoker students. J Altern Complement Med. 2021 February.

16. Malekinezhad H, Moflehi D, Abbasi H, Behzadi A. Effect of low or high volume of high-intensity interval training protocols on the leptin and lipid profile in men with type 2 diabetes. J Community Health Res. 2019 Oct-Dec; 8(4): 228-6.

17. de Oliveira DS, Borges IBP, de Souza JM, Gualano B, Pereira RMR, Shinjo SK. Exercise training attenuates insulin resistance and improves $\beta$-cell function in patients with systemic autoimmune myopathies: a pilot study. Clin Rheumatol. 2019 Aug 10; 38(12): 3435-2.

18. Nasif S, Halawa F, Fouad A, Abdel Hafez H, Kamel A, Rezk Allah S. Effect of aerobic exercise on patients with chronic non-cirrhotic active hepatitis c virus (HCV). Med J Cairo Univ. 2009; 77: 81-7.

19. El-Kader SMA, Al-Jiffri OH, Al-Shreef FM. Liver enzymes and psychological well-being response to aerobic exercise training in patients with chronic hepatitis C. Afr Health Sci. 2014 Jun 12; 14(2): 414-9.

20. Draz RS, Serry ZM, Rahmy AF, El Bardesi MS, Taha MM. Electroacupuncture versus aerobic interval training on liver functions in patients with nonalcoholic fatty liver. J Altern Complement Med, 2020 Jan 20; 26(1): 51-7.

21. Hickman IJ, Jonsson JR, Prins JB, Ash S, Purdie DM, Clouston AD, et al. Modest weight loss and physical activity in overweight patients with chronic liver disease results in sustained improvements in alanine aminotransferase, fasting insulin, and quality of life. Gut. 2004; 53(3): 413-9.

22. El-Kader SM, Saiem-Aldahr MH, Al-Jiffri OH. Aerobic exercise training modulates biochemical parameters in type 2 diabetic patients with chronic hepatitis C. Eur J Gen Med. 2017; 14(2): 43-6.

23. Konishi I, Hiasa Y, Tokumoto Y, Abe M, Furukawa S, Toshimitsu K, et al. Aerobic exercise improves insulin resistance and decreases body fat and serum levels of leptin in patients with hepatitis $\mathrm{C}$ virus. Hepatol Res. 2011 Oct; 41(10): 928-5.

24. McKenna O, Cunningham C, Gissane C, Blake C. Management of the extrahepatic symptoms of chronic hepatitis $C$ : feasibility of a randomized controlled trial of exercise. Am J Phys Med Rehab. 2013 June; 92(6): 504-12.

25. Afkhami F, Fattahi Bafghi A, Abbasi Bafghi H. The effect of eight-week combined exercise training program with sweet almond supplementation on plasma 
levels of leptin and orexin in overweight women. J Nutr Food Security. 2019 Oct 30; 4(4): 218-4.

26. Rostamizadeh M, Elmieh A, Rahmani Nia F. Effects of aerobic and resistance exercises on anthropometric indices and osteocalcin, leptin, adiponectin levels in overweight men. J Arak Univ Med Sci. 2019; 22(1): 85-5.

27. Tartibian B, Sharifi H, Ebrahemi-Torkmani B. Effects of one period of moderate exercise (MI) on serum levels of leptin, blood lactate, lipid profiles and lung function in obese sedentary men. Med J Tabriz Univ Med Sci Health Services. 2019: 41(6), 33-1.

28. Abedi B, Ebrahimimonfared M, Sayyah M. Effects of aerobic versus resistance training on serum leptin and insulin resistance in healthy sedentary men. Hormozgan Med J. 2019; 23(1).
29. Park JH, Kim HJ, Han A, Kang DM, Park S. Effects of aerobic exercise training on the risk factors for liver diseases in elderly women with obesity and impaired fasting glucose: A pilot study. J Exerc Nutr Biochem. 2019 Mar; 23(1): e86831.

30. Ahmadizad S, Ghorbani S, Ghasemikaram M, Bahmanzadeh M. Effects of short-term nonperiodized, linear periodized and daily undulating periodized resistance training on plasma adiponectin, leptin and insulin resistance. Clin Biochem. 2014 Apr; 47(6): 417-2.

31. Tsai CL, Pai MC, Ukropec J, Ukropcová B. Distinctive effects of aerobic and resistance exercise modes on neurocognitive and biochemical changes in individuals with mild cognitive impairment. Curr Alzheimer Res. 2019 Apr 1; 16(4): 316-32. 